\title{
Constitutive Model of Particulate-Reinforced Nanocom- posites for Thixotropic Plastic Forming
}

\author{
Yan Hong ${ }^{1,2}, \quad$ Qiu Hongxu ${ }^{1,2}, \quad$ Liu Shaoping ${ }^{1,2}, \quad$ Hu Zhi ${ }^{1,2}$ \\ ${ }^{1}$ Nanchang University, Nanchang 330031, China; ${ }^{2}$ Key Laboratory of Light Alloy Preparation \& Processing in Nanchang City, Nanchang \\ 330031, China
}

\begin{abstract}
With the consideration of Orowan strengthening effect, a new constitutive model of particulate-reinforced magnesium matrix nanocomposites for thixotropic plastic forming was derived by analyzing relationships among parameters (stress $\sigma$, strain $\varepsilon$, strain rate $\dot{\varepsilon}$, liquid phase rate $f_{\mathrm{L}}$, volume fraction of nano-reinforcement $f_{\mathrm{p}}$, temperature $T$ ). The multiple nonlinear regression method was used to determine the parameters in the constitutive model. A specific constitutive model of SiCp/AZ61 nanocomposites in thixotropic plastic forming was proposed. The calculated values obtained from the constitutive model are in good agreement with the experimental results. Therefore, the constitutive model provides references for the thixotropic forming theory, simulation and fabrication of nanocomposites.
\end{abstract}

Key words: nanocomposites; thixotropic plastic forming; constitutive relationship; Orowan strengthening effect

Magnesium based alloys have widespread applications, especially in the automotive industries, due to their excellent combination of mechanical properties and die castability. It is particularly worth mentioning that their density is significantly lower than that of aluminum or copper $^{[1,2]}$. As it's known to all, micron size ceramic particles which possess low density, stiffness and creep resistance, are added into magnesium based alloys to enhance their mechanical properties. Nevertheless, the ductility of the matrix would be reduced due to the additions of micron size ceramic particles, which limits their applications where good ductility is required ${ }^{[3]}$.

Particulate-reinforced magnesium matrix nanocomposites (MMNCs), in which the reinforcement particle size is less than $100 \mathrm{~nm}$, are most promising high performance materials with unique mechanical and physical properties. It has been shown that MMNCs balance mechanical properties between nano- and micro-structured materials, i.e., ultimate tensile strength and ductility, $0.2 \%$ yield strength, Young's modulus and enhanced hardness ${ }^{[4,5]}$.
The mechanical properties of nanocomposites depend on many factors, including properties of the matrix, processing method, grain size of the matrix, and reinforcement phase properties such as strength and coefficient of thermal expansion. Recently, semi-solid metal processing techniques have been developed to manufacture wrought magnesium or aluminium alloys, of which thixoforming exhibits both matured technology and obvious economical benefit. Thixoforming is extensively employed to form magnesium or aluminium alloys directly into near-net shape components $^{[6-8]}$.

Constitutive modeling of MMNCs for thixoforming is a suitable approach to facilitate the development of thixoforming, and it is especially important for designing a composite for sensitive applications with high experimental costs and predicting the mechanical properties of MMNCs as a function of processing conditions, reinforcement and matrix. H. Yan ${ }^{[9,10]}$ et al. investigated the magnesium matrix composites thixotropic plastic deformation behavior, and the corresponding constitutive model was established. G.

$\overline{\text { Received date: October 20, }} 2015$

Foundation item: National Natural Science Foundation of China (51364035, 51165032); Loading Program of Science and Technology of College of Jiangxi Province (KJLD14003)

Corresponding author: Yan Hong, Ph. D., Professor, Department of Materials Processing Engineering, School of Mechanical and Electrical Engineering, Nanchang University, Nanchang 330031, P. R. China, Tel: 0086-791-83968873, Fax: 0086-791-83969622, E-mail: yanhong_wh@163.com 
Bao et al. ${ }^{[1]}$ carried out a micromechanics study of ceramic particle reinforced metal matrix composites for the high strain rate deformation. In order to predict the rate-dependent plastic flow behavior of the metal matrix composite, a constitutive formula was established. A. Sanaty-Zadeh ${ }^{[12]}$ has investigated the sole or mixed effects of different active strengthening mechanisms (Orowan, load bearing modeling, Hall-Petch and CTE mismatch) to predict the properties of particulate-reinforced magnesium matrix nanocomposites, by Clyne approach.

However, researches on developing the constitutive model of MMNCs for thixotropic plastic deforming have not been reported yet. In this study, a new constitutive model was developed.

\section{Establishment of Constitutive Model}

Based on the analyses of the compression behavior of micro sized particulate reinforced composites for thixotropic plastic deformation, it is found that there exists a certain nonlinear relationship among temperature $T$, strain $\varepsilon$, strain rate $\dot{\varepsilon}$, stress $\sigma$, and liquid phase rate $f_{\mathrm{L}}$. Consequently, the constitutive relationship of micro sized particulate reinforced composites for thixotropic plastic forming was proposed by $\mathrm{H}$. Yan et $\mathrm{al}^{[10]}$, as shown in following equation:

$$
\begin{gathered}
\sigma \propto \exp \left(a+b f_{\mathrm{p}}+c f_{\mathrm{p}}^{2}+d / T\right) \cdot \varepsilon^{n} \cdot \dot{\varepsilon}^{m} \cdot\left[1-\beta f_{\mathrm{L}}\right]^{a_{1}} . \\
{\left[1+(\alpha \dot{\varepsilon})^{m} f_{\mathrm{p}}\right]^{a_{2}}}
\end{gathered}
$$

where $f_{\mathrm{L}}$ can be calculated as:

$$
f_{\mathrm{L}}=\left(\frac{T_{\mathrm{M}}-T_{\mathrm{L}}}{T_{\mathrm{M}}-T}\right)^{\frac{1}{1-K}}
$$

Where $a, b, c, d, a_{1}$ and $a_{2}$ are constants; $n$ is the strain hardening index; $m$ is the strain rate sensitivity index; $\beta$ is the geometric parameter, $\alpha$ is the correction coefficient; $f_{\mathrm{p}}$ is the volume fraction of micro sized particles in the matrix composite; $f_{\mathrm{L}}$ is the volume fraction of liquid phase; $T_{\mathrm{M}}$ is the melting point of pure metal; $T_{\mathrm{L}}$ is the liquids temperature of base alloy; $K$ is the equilibrium distribution coefficient.

Z. Zhang and D. L. Chen have investigated the effects of Orowan strengthening mechanics in nano particulate reinforced magnesium matrix nanocomposites (particle size ranges from 20 to $100 \mathrm{~nm})^{[13]}$. And the results indicate that the Orowan strengthening effect plays a crucial role at strengthening the yield strength in MMNCs and the strengthening effect increases with decreasing the size of nanoparticles. Subsequently, a constitutive relationship of MMNCs for predicting yield strength of intra-granular type is summarized as follows:

$$
\sigma_{\mathrm{yc}}=\sigma_{\mathrm{ym}}\left(1+f_{1}\right)\left(1+f_{\mathrm{d}}\right)\left(1+f_{\text {Orowan }}\right)
$$

$$
f_{\text {Orowan }}=\frac{2 G_{\mathrm{m}} b}{\sigma_{\text {ym }}\left(\pi / 6 f_{\mathrm{b}}\right)^{1 / 3} d_{\mathrm{p}}}
$$

Where $\sigma_{\mathrm{yc}}$ is the yield strength of MMNCs; $\sigma_{\mathrm{ym}}$ is the yield strength of the magnesium matrix alloy under the same processing conditions as those of MMNCs; $f_{1}$ is the improvement factor in consequence of the load-bearing effect; $f_{\mathrm{d}}$ is the improvement factor related with the enhanced dislocation density in the matrix induced by the thermal mismatch between the reinforcement particles and the matrix; $f_{\text {Orowan }}$ is the improvement factor associated with the Orowan strengthening effect; $f_{\mathrm{p}}$ is the volume fraction of reinforcement nanoparticles; $G_{\mathrm{m}}$ is the shear modulus of the magnesium matrix; $b$ is the magnitude of the Burgers vector of dislocations in the magnesium matrix; $d_{\mathrm{p}}$ is the particle size.

With the consideration of Orowan strengthening effect, the constitutive model of composites reinforced with nanoparticles for thixotropic plastic deformation is proposed as follows:

$$
\begin{gathered}
\sigma=\exp \left(a+b f_{\mathrm{p}}+c f_{\mathrm{p}}^{2}+d / T\right) \cdot \varepsilon^{n} \cdot \dot{\varepsilon}^{m} \cdot\left[1-\beta f_{\mathrm{L}}\right]^{a_{1}} . \\
{\left[1+(\alpha \dot{\varepsilon})^{m} f_{\mathrm{p}}\right]^{a_{2}}\left[1+\lambda f_{\mathrm{p}}^{1 / 3}\right]^{a_{3}}} \\
\left(\lambda=\frac{2 G_{\mathrm{m}} b}{G(\pi / 6)^{1 / 3} d_{\mathrm{p}}}\right)
\end{gathered}
$$

For the intra-granular type of MMNCs in this experiment, the volume fraction of nanoparticles is relatively low, typically about $0.27 \% \sim 1.12 \%$. Therefore its quadratic form $c f_{\mathrm{p}}^{2}$ shall be excluded from consideration. The final form of constitutive model is established as follows:

$$
\begin{aligned}
\sigma= & \exp \left(a+b f_{\mathrm{p}}+d / T\right) \cdot \varepsilon^{n} \cdot \dot{\varepsilon}^{m} \cdot\left[1-\beta f_{\mathrm{L}}\right]^{a_{1}} . \\
& {\left[1+(\alpha \dot{\varepsilon})^{m} f_{\mathrm{p}}\right]^{a_{2}}\left[1+\lambda f_{\mathrm{p}}^{1 / 3}\right]^{a_{3}} }
\end{aligned}
$$

\section{Solution for Parameters in Constitutive Model}

In order to determine the parameters in the constitutive model, the multiple nonlinear regression method was used. And Eq.(6) can be transformed into a linear one after taking logarithm.

$$
\begin{aligned}
\ln \sigma= & a+b f_{\mathrm{p}}+c / T+n \ln \varepsilon+m \ln \dot{\varepsilon}+a_{1} \ln \left(1-\beta f_{\mathrm{L}}\right) \\
& +a_{2} \ln \left[1+(\alpha \dot{\varepsilon})^{m} f_{\mathrm{p}}\right]+a_{3} \ln \left(1+\lambda f_{\mathrm{p}}^{1 / 3}\right)
\end{aligned}
$$

Where

$$
\begin{aligned}
& y=\ln \sigma, X_{1}=f_{\mathrm{p}}, X_{2}=1 / T, X_{3}=\ln \varepsilon \\
& X_{4}=\ln \dot{\varepsilon}, X_{5}=\ln \left(1-\beta f_{\mathrm{L}}\right) \\
& X_{6}=\ln \left[1+(\alpha \dot{\varepsilon})^{m} f_{\mathrm{p}}\right], X_{7}=\ln \left(1+\lambda f_{\mathrm{p}}^{1 / 3}\right) \\
& A_{0}=a, A_{1}=b, A_{2}=c, A_{3}=n, A_{4}=m \\
& A_{5}=a_{1}, A_{6}=a_{2}, A_{7}=a_{3}
\end{aligned}
$$


Therefore, Eq.(7) can be changed into the following form:

$$
\begin{aligned}
y= & A_{0}+A_{1} X_{1}+A_{2} X_{2}+A_{3} X_{3}+A_{4} X_{4}+A_{5} X_{5}+ \\
& A_{6} X_{6}+A_{7} X_{7}
\end{aligned}
$$

\section{Constitutive Relationship of SiCp/AZ61 Nanocomposites for Thixotropic Plastic Forming}

The data $\left(\sigma, \dot{\varepsilon}, \varepsilon, T, f_{\mathrm{L}}, f_{\mathrm{P}}\right)$ in the constitutive relationship were gained based on the thixotropic compression of $\mathrm{SiC}_{\mathrm{p}} / \mathrm{AZ61}$ nanocomposites. A more detailed description of the experiment was previously reported by us ${ }^{[14]}$. The $\mathrm{SiC}$ powder with a mean particle size of $100 \mathrm{~nm}$ was added into AZ61 matrix uniformly. Statistical package for the social sciences (SPSS) was applied to make the regression calculation and analysis for the above linear Eq. (9). Table 1 lists the common statistical values, including the correlation coefficient $R$, determination coefficient $R^{2}$, adjusted determination coefficient $\bar{R}^{2}$ and the standard error of the estimate $S$. $A_{4}$ (the number $m$ ) was calculated by repeated selection of $\alpha$ (the correction coefficient) to be in accordance with the number $m$ in $X_{6}\left(\ln \left[1+(\alpha \dot{\varepsilon})^{m} f_{\mathrm{p}}\right]\right)$. The best fit correction coefficient $(\alpha=58)$ was obtained. Since the equation, as shown in Eq.(9) has lots of explained variables, these explained variables should be depended on the adjusted determination coefficient $\bar{R}^{2}$. As shown in Table $1, \bar{R}^{2}$ is close to 1 and it implies that its fit degree is high. Consequently, we can conclude that the proposed constitutive model is reliable and can give accurate and stable results.

Table 2 shows the analysis results of variance. Residual and regression in sum of squares are 2.826 and 22.847 , respectively, and the total is 25.673. Meanwhile, residual and regression of mean square are 0.046 and 3.264 , respectively.

Standard error of unstandardized coefficients (Std. Error), unstandardized coefficients $(B)$, standardized coefficients, observed value $(t)$ of test statistics in the significance test of regression coefficient and the concomitant probability value (Sig.) are shown in Table 3. And the value of the corresponding variable regression coefficient can be derived from Table 3, as shown in follows: $X_{0}=-5.768, X_{1}=14.158$,
$X_{2}=3674.674, X_{3}=-0.535, X_{4}=0.245, X_{5}=6.076, X_{6}=-1.663$, $X_{7}=17.834$. The fact that the concomitant probability (Sig.) approximately equals to 0 indicates that it has significant regression. When compared with the regression coefficients, the sensitivity coefficient $m\left(X_{4}=0.245\right)$ of strain rate which was determined by regressing is in good agreement with the replaced value $(m)$.

Consequently, the following formula is got from Eq. (9).

$$
\begin{aligned}
& y=-5.768-14.158 X_{1}+3674.674 X_{2}-0.353 X_{3}+ \\
& 0.245 X_{4}+6.076 X_{5}-1.663 X_{6}+17.834 X_{7}
\end{aligned}
$$

By means of the inverse process of converting Eqs.(7) to (9), Eq.(11) was acquired from Eq. (10), as shown in follows:

$$
\begin{aligned}
& \sigma=\exp \left(-5.768+-14.158 f_{\mathrm{p}}+3674.674 / T\right) \cdot \varepsilon^{-0.353} \\
& \dot{\varepsilon}^{0.245} \cdot\left[1-\beta f_{\mathrm{L}}\right]^{6.076} \cdot\left[1+(58 \dot{\varepsilon})^{0.245} f_{\mathrm{p}}\right]^{-1.663} \\
& {\left[1+0.627 f_{\mathrm{p}}^{1 / 3}\right]^{17.834}}
\end{aligned}
$$

Eq.(11) is the constitutive relationship of $\mathrm{SiC}_{\mathrm{p}} / \mathrm{AZ61}$ nanocomposites for thixotropic plastic forming.

\section{Validation of Constitutive Model of $\mathrm{SiC}_{\mathrm{p}} /$ AZ61 Nanocomposites for Thixotropic Plastic Forming}

Fig.1 shows comparisons between predicted and experimental results in thixotropic plastic compression

Table 1 Constants used for the statistical calculation

\begin{tabular}{ccccc}
\hline Model & $R$ & $R^{2}$ & $\bar{R}^{2}$ & $S$ \\
\hline 1 & 0.943 (a) & 0.890 & 0.977 & 0.22196 \\
\hline
\end{tabular}

a. Predictors: (Constant) $X_{7}, X_{6}, X_{5}, X_{4}, X_{2}, X_{1}, X_{3}$;

\begin{tabular}{|c|c|c|c|c|c|c|}
\hline \multirow{2}{*}{ Model } & & \multicolumn{2}{|c|}{ Unstandardized coefficients } & \multirow{2}{*}{ Standardized coefficients } & \multirow{2}{*}{$t$} & \multirow{2}{*}{ Sig. } \\
\hline & & $B$ & Std. error & & & \\
\hline \multirow[t]{8}{*}{1} & $X_{0}($ Constant $)$ & -5.768 & 4.631 & 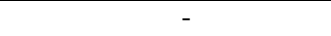 & -1.246 & 0.218 \\
\hline & $X_{1}$ & 14.158 & 56.193 & -0.53 & -0.252 & 0.802 \\
\hline & $X_{2}$ & 3674.674 & 2312.933 & 0.210 & 1.59 & 0.118 \\
\hline & $X_{3}$ & -0.535 & 0.031 & -5.000 & 11.277 & 0.000 \\
\hline & $X_{4}$ & 0.245 & 0.036 & 0.708 & 6.835 & 0.000 \\
\hline & $X_{5}$ & 6.076 & 1.661 & 0.490 & 3.657 & 0.001 \\
\hline & $X_{6}$ & -1.663 & 0.996 & -0.188 & -1.670 & 0.100 \\
\hline & $X_{7}$ & 17.834 & 6.367 & 0.472 & 2.242 & 0.029 \\
\hline
\end{tabular}

b. Dependent variable: $y$

Table 2 ANOVA (b)

\begin{tabular}{clccccc}
\hline \multirow{2}{*}{ Model } & & $\begin{array}{c}\text { Sum of } \\
\text { squares }\end{array}$ & df & $\begin{array}{c}\text { Mean } \\
\text { square }\end{array}$ & $F$ & Sig. \\
\hline \multirow{2}{*}{1} & Regression & 22.847 & 7 & 3.264 & 66.975 & $0.000(\mathrm{a})$ \\
& Residual & 2.826 & 58 & 0.046 & - & - \\
& Total & 25.673 & 65 & - & - & - \\
\hline
\end{tabular}

a. Predictors: (Constant) $X_{7}, X_{6}, X_{5}, X_{4}, X_{2}, X_{1}, X_{3}$;

b. Dependent variable: $y$

Table 3 Coefficients (a)

a. Dependent variable: $y$ 


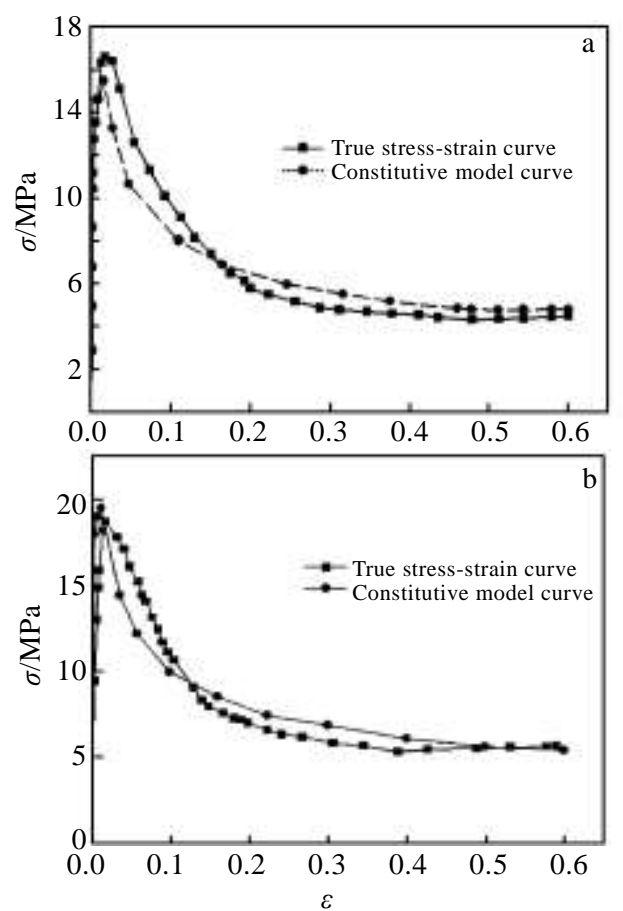

Fig.1 Validation of constitutive model: (a) $1 \mathrm{wt} \% \mathrm{SiC}_{\mathrm{p}} / \mathrm{AZ61}$, $535^{\circ} \mathrm{C}, 0.1 \mathrm{~s}^{-1}$; (b) $2 \mathrm{wt} \% \mathrm{SiC}_{\mathrm{p}} / \mathrm{AZ61}, 550^{\circ} \mathrm{C}, 1 \mathrm{~s}^{-1}$

processes. The solid lines are the experimental curves, and the dotted lines are the predicted ones. As shown in Fig.1, the results predicted by Eq.(10) agree with the experimental results. It indicates that the proposed constitutive model has fairly high level of forecast precision and practical significance for guiding the thixotropic plastic deformation process of nanocomposites.

\section{Conclusions}

1) The multiple nonlinear regression method is used to develop the constitutive model of particulate-reinforced nanocomposites for thixotropic plastic forming. This was done by taking Orowan strengthening effects into account. The calculated values obtained from the constitutive model are in good agreement with the experimental results.

2) The constitutive model has fairly high level of forecast precision and practical significance for guiding the thixotropic plastic deformation process of nanocomposites.

\section{References}

1 Fink R. In Kainer $\mathrm{K}$ U ed. Die-Casting Magnesium, Magnesium-Alloys and Technologies[M]. Germany: WileyVCH Verlag GmbH \& Co, 2003: 23

2 Yan H, Hu X W, Nie Q et al. China Foundry[J], 2011, 8: 269

3 Lim S C V, Gupta M, Lu L. Materials Science and Technology[J], 2001, 17: 823

4 Zhang Z, Chen D L. Scripta Materialia[J], 2006, 54: 1321

5 Nie K B, Wang X J, Wu K et al. Journal of Alloys and Compounds[J], 2011, 509: 8664

6 Yan H, Zhou B F. Solid State Phenomenon[J], 2006, 116-117: 639

7 Yan H, Zhang F Y. Fabrication and Thixotropic Plastic Forming of Particulate-Reinforced Composites[M]. Beijing: National Defense Industry Press, 2013 (in Chinese)

8 Kim S K, Kim Y J. Materials Transactions[J], 2001, 42: 1277

9 Yan H, Wang J J. Transactions of Nonferrous Metals Society of China[J], 2010, 20(S): 811

10 Yan H, Wang J J, Zhang F Y. Advanced Materials Research[J], 2011, 154-155: 690

11 Bao G, Lin Z. Acta Materialia[J], 1996, 44: 1011

12 Sanaty-Zadeh A. Materials Science and Engineering $A[\mathrm{~J}]$, 2012, 531: 112

13 Zhang Z, Chen D L. Materials Science and Engineering A[J], 2008, 483-484: 148

$14 \mathrm{Hu} \mathrm{Z}$, Yan H, Liu S P et al. Journal of Mechanical Engineering[J], 2010, 46: 28

\title{
纳米颗粒增强镁基复合材料触变成形本构模型
}

\author{
问 洪 ${ }^{1,2}$, 邱鸿旭 ${ }^{1,2}$, 刘少平 ${ }^{1,2}$, 胡 志 ${ }^{1,2}$ \\ (1. 南昌大学, 江西 南昌 330031) \\ (2. 轻合金制备及成型重点实验室, 江西 南昌 330031)
}

\begin{abstract}
摘 要: 通过分析纳米颗粒增强镁基复合材料半固态触变塑性成形中不同因素（应力 $\sigma$ 、应变 $\varepsilon$ 、应变速率 $\dot{\varepsilon}$ 、温度 $T$ 、液相分数 $f_{\mathrm{L}}$ 、 增强颗粒体积分数 $f_{\mathrm{p}}$ ) 之间的关系，同时考虑 Orowan 增强机制，由此提出一种新的本构模型。该本构模型中各参数由多元非线性回 归法演算而得。触变塑性成形实验数据与数值模拟数据吻合良好, 证明推导的本构关系可用于触变塑性成形的数值模拟, 并可用来指 导复合材料的触变塑性成形工程实践。
\end{abstract}

关键词: 纳米复合材料; 触变成形; 本构关系; Orowan 增强机制

作者简介: 间 洪, 男, 1962 年生, 教授, 南昌大学机电工程学院材料加工工程系, 江西 南昌 330031, 电话: 0791-83968873, 传 
Li Hai et al. / Rare Metal Materials and Engineering, 2016, 45(10): 1938-1942

真: 0791-83969622, E-mail: yanhong_wh@163.com 